\title{
Research on the Diversified Development of Energy System in China
}

\author{
Yiming Zhang ${ }^{*}$ \\ University of California, College of Engineering, Davis, US, 95616.
}

\begin{abstract}
With faster industrial development, the demand for energy increases dramatically. As demand rises, the supply of energy grows a lot. Although with new technologies, traditional energy, such as burning coal, is still the main way of producing energy. Traditional production has a huge and irreversible hurt to the environment, which should be substituted by new clean energy. Finding out the new resources and making them work in the real energy market is the primary goal of energy development. This article mainly describes the current status of China's natural clean energy, and then combines the advantages and disadvantages of many aspects and proposes several methods suitable for the multiple development of energy. Comprehensively considering the clean and high-efficiency characteristics of future energy development, a circular model of energy consumption and production capacity has been formed in all aspects, reducing energy waste and increasing energy consumption restrictions due to instability. In view of the development characteristics of China's existing vast land and resources, and the huge energy demand groups, small-quantity, multi-site and diverse energy development is the future trend of China's energy development. However, the existing utilization and utilization rate of these natural resources are very low, and although a large number of traditional production capacity industries can meet the energy supply demand, they have a great impact on the environment. President Xi once said that green waters and green mountains are our golden and silver mountains. Such environmentally friendly energy development is the ultimate goal we want to achieve.
\end{abstract}

\section{Introduction}

During energy development, low carbon-cost and high efficiency are the critical points and the principle of energy production. As President $\mathrm{Xi}$ mentioned in the General Debate of the Seventy-fifth United Nations General Assembly, China will reach carbon neutrality before 2060[1]. The clean energy source is pushed as the first consideration during energy production. However, for the huge demand for the energy market, a completely clean and individual way of energy production is not enough. The only way for improvement is to decrease the percentage of traditional energy resources during production.

The diversity of energy development is the result of both pursuing eco-friendliness and combining the reality of requirement. And focusing on the distribution of cities in China, the different modes of energy development are necessary for the energy balance to fulfill the demand for energy from different places. Also, the huge disadvantages existed in every method of energy production avoid too much reliance on one energy resource. Until the sound of new energy which is dramatically perfect, developing several energy sources simultaneously is the best choice for future work. From the technique aspect, the efficiency of energy production is a breakout of future energy development. It has a huge developing space and multiple solutions, at last, the main problem of those clean energy is pollution and the lack of stability. It could be solved by the combination of multiple energy sources.

\section{Multiple energy production}

Hydro power refers to the use of energy in water systems. The process has no other chemical or polluted materials produce and it can all build on the natural existed water system, which is an abundant source in China. However, there are plenty of drawbacks. The positions of water resources are quite different from the demand for energy for areas. And the cost including time and economy for building dam is too high to sustain the area's long-time electricity usage. Also, seasonal water flux is a potential problem for energy development.

Solar power firstly gets light pollution for both urban life and any aviation activities. The process needs material like silicone, which is highly polluted without a great deal of wastes. The transfer efficiency limits its usage for the main energy provision.

Even though wind power seems to have many advantages as hydro and solar energy do, the unstable property is still a challenge. Unreliable time for wind requires a good technique for the storage of energy. The

\footnotetext{
Corresponding author: yimzhang@ucdavis.edu
} 
noise pollution is still pollution for people and normal producing life.

\section{Several breakout of energy development}

\subsection{Huge transformation of location}

With the strong infrastructure of energy transformation in China, the energy can be sustainable for different kinds of places without the limitation of the energy producing position. And now nearly every city and town in China are having its energy grid, which is strong insurance for future usage of energy. The seaside energy and inner side energy can be used to balance the difference in energy production.
In many cases, most of the energy distribution in China is in the east and a small part of the west. However, in terms of energy resources, the resources in the west are relatively more than those in the east. Therefore, the combination of the application of the West-East Power Transmission Project and energy production can form a good energy network. The east is mainly rich in tidal energy, the west is mainly rich in solar and wind energy, and the altitude fault in the middle has a lot of water resources. Each region puts a large amount of energy into production, and then transports and allocates balance.

This strong advantage declines the limitation of using hydro, solar, and wind power from a special place. The future energy grid will become a star type, which concentrates one way of energy production and maximize the profits and superiority of every place.

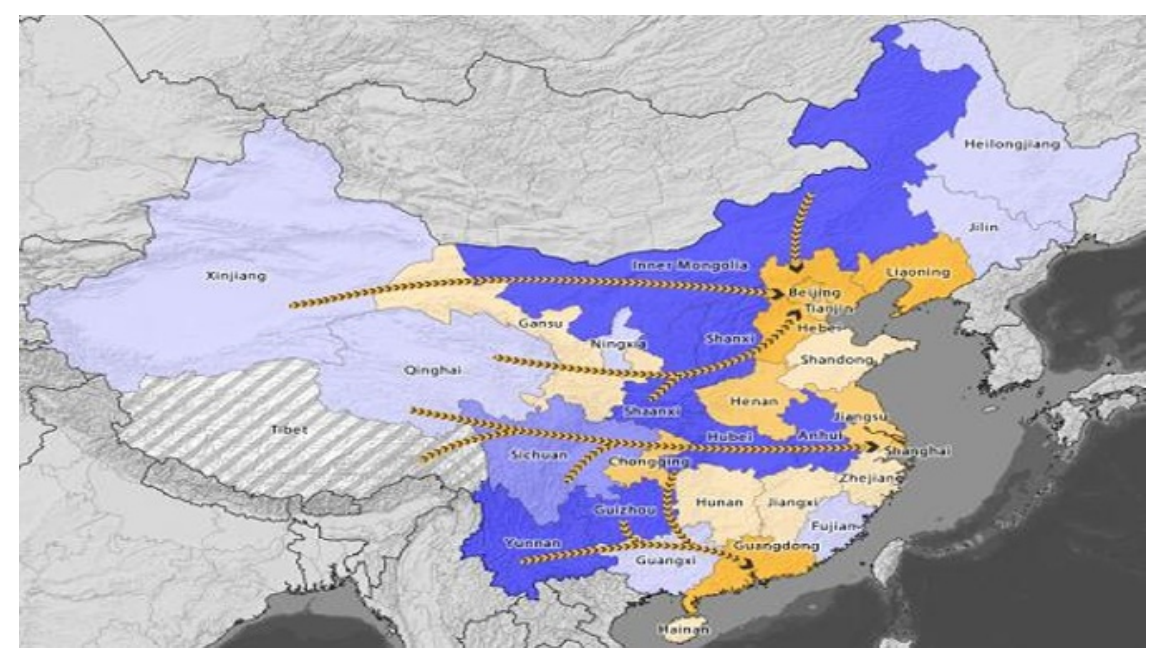

Figure 1. China's West-East Power Transmission

\subsection{Abundant natural sources}

China's river hydropower reserves are 676 million kW, the installed capacity of possible hydropower resources is 378 million $\mathrm{kW}$, and the annual power generation capacity is 1,920 billion $\mathrm{kWh}$. The annual solar radiation energy received by China's land surface is about $50 \times 10^{\wedge} 18 \mathrm{~kJ}$. Especially at Lhasa, called Sun City, the annual average sunshine time is $3005.7 \mathrm{~h}$, and the total solar radiation is $816 \mathrm{~kJ} / \mathrm{cm}^{\wedge} 2$. The national wind energy density is $100 \mathrm{~W} / \mathrm{m} 2$, and the total reserves of wind energy resources are about 1.6X105MW[2].

Even though a large number of natural resources cannot be directly equated with a large number of energy resources and their utilization still has a lot of efficiency and other problems, the combination of these clean energy sources and traditional energy sources will improve some of the existing energy production problems and reduce traditional energy sources' percentage.

\subsection{Electricity peak \& valley}

The usage of hydro, solar and wind power perfectly fits the characteristic of the energy market. The energy demand reaches its peak during the noon in the daytime, and the valley happens at midnight. When the time for valley, energy stores, and they are used whenever the energy production is unstable for daytime energy demand.

For these clean energy sources, hydropower projects and tidal energy require the accumulation of potential energy at night, solar energy can only work during the day when the sun is good, and wind energy has an indeterminate time characteristic. When there is a large demand for energy, the energy stored at a specific time is released to maximize the use of energy. In the following, there is an electricity price for each period [3]. When a large number of small electricity users transfer their stored energy to large electricity users during a time when electricity prices are high, accidental energy loss and waste will be avoided to the greatest extent. At a time when electricity prices are low, the fragmented electricity consumption and relative energy storage of small electricity users help the overall energy system to recharge. Such a back-and-forth energy system mimics our natural law, the law of conservation of energy. 


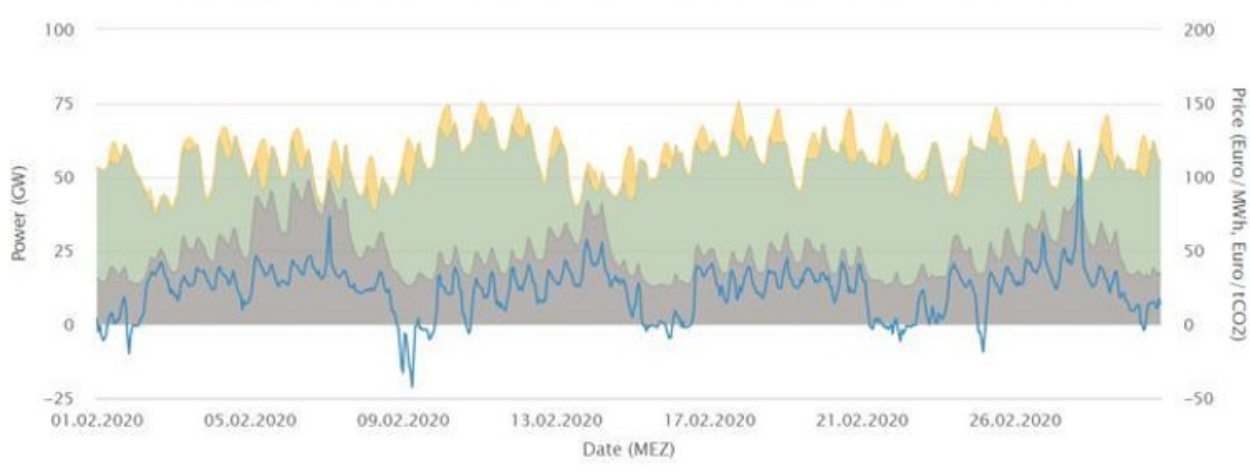

Figure 2. The electricity price for time period[4]

\subsection{Miniaturization of energy production}

Solar and wind power can be installed for every family or some small scale energy factory. This makes sure that every entity can solve the energy demand firstly by themselves and give out multiple sources of energy for the market. Some supply-demand imbalance of energy market can be solved by those principal entities. Small and multiple energy production decreases pollution when they are clean energy and better fit the need of energy usage. The more energy produced by principal entities can be sent back to the big factory for energy use when they are producing the energy during market valley. The transfer of energy between entities and big firms balances the differences in the energy market.

These clean energy sources can be produced in individual or small power generation sources with the advantage of being able to produce in small quantities. Such a small-quantity production model helps these scattered natural clean energies to bring energy to various regions, and the relatively small production method solves the pollution problem in the production process. And combined with the peaks and valleys of energy mentioned above, the front and back deployment of energy has been best realized. For example, in Lhasa, many residents have installed solar-powered generators in their homes. They are self-sufficient in many cases and supplement the overall energy system when the large system energy is lacking. Such a small-scale production capacity reduces all the problematic output of energy production but increases the benefits of its production capacity. Although such cases now only occur in areas with great natural energy advantages like Lhasa, the promotion of this energy model is feasible for common cities. Now the technology of solar absorption panels is making rapid breakthroughs, and smaller and smaller solar panels are used in production capacity. Even in the face of relatively densely populated large cities, such small individual power generation is feasible in terms of space and economic benefits.
Moreover, in large-capacity factories, small-scale production is also in line with the characteristics of China's existing natural energy resources. Because of the wide area and scattered resources, like water resources, they are too scattered in China. If all the production capacity is applied to some large river basins or drainage, it is a huge expense, which is beneficial in terms of economy and energy efficiency. Moreover, the single water resource makes seasonal instability a great obstacle to energy supply. However, the scattered small hydropower stations meet the energy demand well, and at the same time, the waters in different locations can guarantee the energy supply of the overall system at different times. In Sichuan, the province has the most water resources in China, the Xiluodu Power Station and Xiangjiaba Power Station, the second and third largest hydropower station in Sichuan Province, were put into operation. The total installed capacity of the two power stations reached 20.26 million kilowatts, which is equivalent to another Three Gorges power station[5]. And in Sichuan, there are thousands of hydropower stations for different scales.

There are now a large number of small-quantity hydropower designs in the United States. The small-quantity hydropower station is a mature design, which has high economic benefits while maintaining minimal environmental impact. These small-scale hydropower plants are also a self-sufficient operation model in the United States. Due to regional and transportation restrictions, most of this output energy is used in some production needs nearby, and not through the complicated traditional electricity sales model. Such small-quantity hydropower stations do not need to pay taxes to the government, and then digest the production capacity at internal prices, forming a good power supply mode. Such a successful example of small quantitative production capacity is what China can learn from now, and it is extremely in line with some local characteristics of China. 


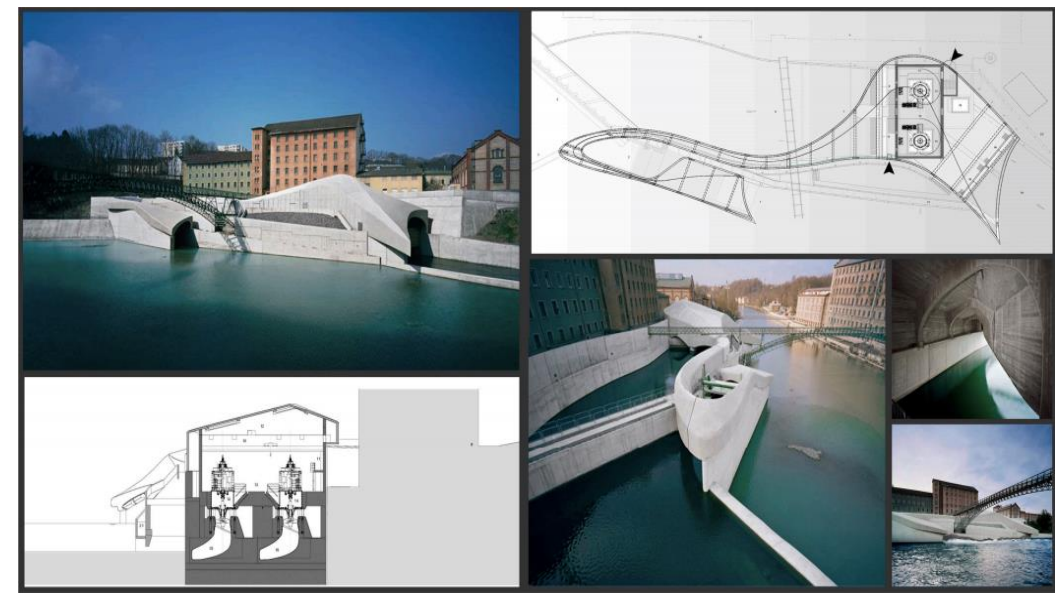

Figure 3. Example of a small hydropower plant of recent construction. The hydropower station in Kempten (2010)[6]

\section{[ Combination}

So with all kinds of natural energy, the schedule and transformation between cities allow that every way of energy production makes up other disadvantages caused by others. In a complete daytime, every energy production has its own time to build up the energy transferring system. From midnight to the early morning, the wind power stores energy, which is at the time with low energy demand and full of wind. And the water system uses the energy left to create the potential energy for daytime employment. Then moving to the daytime, solar energy mainly sustain the energy demand. And the energy stored by the wind and hydro power work as a second choice for the market. Also, for the highest energy cost time, 7-9 am and 5-7 pm, the tide energy fits the need there and sustains the energy use. So, the connection between different kinds of energy resources strongly fills the vacancy of energy provision caused by clean energy. For every small entity with their self-producing devices, they use energy from the big firm during the peak of energy usage. When the energy demand down to the valley, they sell out their surplus energy, then collect together to satisfy the need from the market. Energy monetization helps to solve the unstable property for clean energy use.

In Lhasa, such a power operation mode is also being gradually implemented. The extremely high altitude itself limits the support of traditional energy sources for energy supply, so a variety of diversified production capacity measures are used in both individual electricity users and large-scale production. Most of the domestic electricity is at a self-sufficient level, and many households can supply electricity back to the local power supply company, in which they can also be compensated for before and after electricity prices. Such an energy allocation model is not only an improvement in energy efficiency and total supply but also an improvement in energy economic efficiency. This win-win situation greatly promotes the spread ability of this energy model. And although the advantages and disadvantages of the Lhasa region magnify the benefits of such an energy system and ignore its disadvantages, the current production technology has greatly allowed every small family or every community to have its small-scale production capacity. Like most technologies used in agriculture, energy-converting machines have been reduced to the size of normal households. Moreover, this diversified system fundamentally avoids the shortage of natural resources in some cities and maximizes the advantages of the region.

\section{प Conclusion}

The future energy blueprint is an energy flow system. Not only one but multiple energy production maximizes their advantages and minimizes their drawbacks to reach the goal of a clean and rich energy supply. The plan is not to move the traditional energy production out of the producing line, instead, we are trying to decrease the percentage of it to control the pollution and ensure the energy demand-supply relationship.

Thanks for the instruction from Professor Budimir Rosic of the University of Oxford and also the assistance from Jiaqi Hu. Teacher Sun's help on paper writing is also helpful for me.

\section{References}

1. Xinhuanet, September 23, 2020 report, http://www.xinhuanet.com/english/2020-09/23/c_13 9388764.htm

2. China National Meteorological Administration display data. http://data.cma.cn/

3. China's West-East Power Transmission

4. He JiJiang, Analysis and Research on Load Curve of German Power System in 2020, 2020

5. Ministry of Water Resources, 2018 Statistical Bulletin of Water Resources Development

6. Marianna Rotilio, Chiara Marchionni and Pierluigi De Berardinis. The Small-Scale Hydropower Plants in Sites of Environmental Value: An Italian Case Study, Sustainability, 2017 